\title{
Customer Segmentation Analysis in Major Sporting Goods Companies and its Influence on Strategic Marketing Decisions
}

\author{
Thomas Rossberger ${ }^{1} \&$ Martin Fiedler ${ }^{2}$ \\ ${ }^{1}$ Department of Business Administration, Nicosia, Cyprus \\ ${ }^{2}$ Process Consultant, Munich, Germany \\ Correspondence: Thomas Rossberger, Department of Business Administration, Nicosia, Cyprus. E-mail: \\ t-rossberger@opis-consulting.de
}

Received: September 22, 2014 Accepted: October 13, $2014 \quad$ Online Published: November 20, 2014

doi:10.5539/res.v6n4p268

URL: http://dx.doi.org/10.5539/res.v6n4p268

\begin{abstract}
This article critically reviews the use of customer segmentation in distribution channels as an analytical instrument to support strategic marketing decisions. Major sporting goods companies with a very fragmented distribution system have been selected as sampling group. With access to the top management, this article gives insight into decision processes and strategies in the sporting goods industry. The study focuses on the analysis of an existing customer portfolio as well as on the future development of individual segments. The research exceeds the reduction of customer segmentation to a "marketing strategy" by showing the impact on structural and strategic decisions of corporations. Thus the scope of this study amplifies considerably the common definitions and objectives of the customer segmentation concept and implicates the deduction of a strategic target as assumed. A qualitative exploratory research design has been chosen and the gained information has been processed with personal in-depth interviews to gather reliable primary data. The findings illustrate that converting customer segmentation into a set of mid-term marketing decisions offers potential for improvement. Marketing and global strategic decisions as well as change management requirements in the sporting goods industry may benefit from this research in adapting their focus.
\end{abstract}

Keywords: customer segmentation analysis, sporting goods companies, marketing, decisions, qualitative research

\section{Introduction}

In many established European markets a hyper-segmentation (Perez, 2008; Berghoff, 2007) can be observed. The term of hyper-segmentation expresses the tendency to a division of markets into many sub-segments or small niches with a high concentration of competing suppliers. Facing a highly-competitive market environment, producers are confronted with limited or declining market shares and permanent pressure on product prices as well as their costs. "Blue oceans" (Kim \& Mauborgne, 2005), the still unexploited markets, are the desire of every sales oriented company. These oceans are difficult to be found or can only be entered by high initial funding. In view of the current global financial-economic situation both the possibility and the willingness for investments into new markets might be considered as limited for most corporations.

The global economic crisis after the year of 2007 has revealed that there have been dynamic and far-reaching changes in the economic environment worldwide (Keegan \& Green, 2010). Starting with a crash in the US real estate business, financial markets in US, Europe and Asia followed within days. Even some national financial markets collapsed and stability could only be assured through the intervention of national central banks or the European Central Bank (ECB) in Frankfurt as well as the International Monetary Fund (IMF) in Washington, D.C. Bankruptcies of worldwide operative corporations and banks, like Lehmann Brothers, followed.

The initial spark of this global economic phenomenon is unrevealed and might well be of complex consistency. Keegan and Green (2010) see companies confronted with new realities today. Firstly, trade is no longer the driving force in the world economy. Nowadays it is the rapid circulation of capital among companies, nations or trade zones. Secondly, the correlation between production and employment is not a valid constant and linear function and more, since productivity has increased steadily over the past few decades. Hence less people in production are able to deliver higher output year for year. Thirdly, the global economy dictates the worldwide 
markets. Fourthly, the struggle between the two doctrines of capitalism and socialism is over, and last but not least, the internet has opened up a tremendous new business potential. The internet does not only offer a 24/7 shopping experience and the appearance of unlimited availability, it is further reducing the importance of national trade barriers. In addition e-commerce has forced companies to adapt or change their business models and develop new adapted strategies (Keegan \& Green 2010). Against this background a more efficient development of existing customer portfolios is gaining of importance as far as the mid-term competitiveness of corporations is concerned. The customer portfolio is thus understood as a synonym for all existing or potentially new customers of a company, in other words the market potential.

Best (2008) underlines the importance of a "customer focused company DNA" even more. In his thinking modern, flexible companies need to accept and react accordingly, since in today's business the only constant is change. This change implies customers, who vary in needs, lifestyle or consumption behaviour. Moreover it continues with the competitors in the market changing their products and erecting barriers to other market players. The entire business environment changes, as economical, political, social and technological developments will remain unpredictable in a long run. Furthermore, Best (2008) correlates these changes with the immanent need for a customer focused strategy in which customer satisfaction is the key element. All levels of a company are in demand and it is starting with a customer focused leadership.

This study aims to identify how leading companies of the sports and lifestyle industry are treating the concept of customer segmentation in their distribution channels. The focus of this research is not of a theoretical approach but furthermore of practical nature in execution of a customer-centric thinking in sports goods companies. Due to the fact that the input for that topic is the result of many years in practice, where the above mentioned theories were developed, a deductive research approach has been chosen. Hence the theory is determined by the conviction that a key element of modern and flexible business management is the customer centric approach. Furthermore the core of customer centric thinking should be based on a consistent enforcement of customer segmentation. In that respect consistency would at least mean influencing all strategic marketing decisions.

\section{Methodology}

\subsection{Research Design}

Malhotra and Dash (2010) differentiate between two qualitative research designs, conclusive and exploratory. A conclusive design is more formal, structured and based on large representative samples. The main objective of conclusive research is to test specific hypotheses and relationships. The results of a study intend to deliver input for management decisions (Malhotra \& Dash, 2010).

Exploratory research designs are meant to provide more insights and understanding of specific research. The research process itself, as well as the information gathered, is typically more flexible. Samples are small and non-representative. In-depth interviews with industry experts are often used to provide the primary data required (Malhotra \& Dash, 2010). Hence an exploratory research approach best meets the intention of this study, which is to gain insight into a defined topic and to develop recommended courses of action.

The research design is focussed on two basic assumptions:

- Many companies are still not aware that segmentation in distribution channels could provide considerable value when creating a new business model.

- Due to a lack of consistency and deficient execution, segmentation models applied in practice have not substantially influenced the mid- term marketing strategy of companies.

Semi-structured in-depth interviews with industry insiders are based on an interview guideline with the following topics:

- background of the company and the executive who will be interviewed

- reasons for the decision to segment customers within the company

- factors influencing success or failure of the segmentation

- influence of the customer segmentation analysis on marketing strategy and organization

- evaluation and outlook

Recordings of the conversations have been carried out by using two technical applications simultaneously to reduce the error rate. The duration of the interviews has been set to a maximum of 45 minutes. In order to include all emotional aspects during the conversation, transcriptions of the recordings were made within two days after the interviews. 
All main areas of interest could be covered based on the interview guideline. Following the principle of a thematic analysis, the transcriptions of the interviews have been evaluated and structured in the following structure:

- detecting patterns

- deriving sub-themes

- relation to literature

- creating a story line

The process followed the interactive model of Miles and Huberman (1994, p.12), which consists of the three link stages or streams, data reduction, data display and data conclusion-drawing and verifying as illustrated below. The model is able to display the reality of interactions from gathering to displaying and from reducing up to interpreting the transcribed interview data. In order to make sure that the excerpt from the interviews contains all relevant results and ideas, the researcher needs to go various times back and forth through the different stages of the Miles and Huberman model.

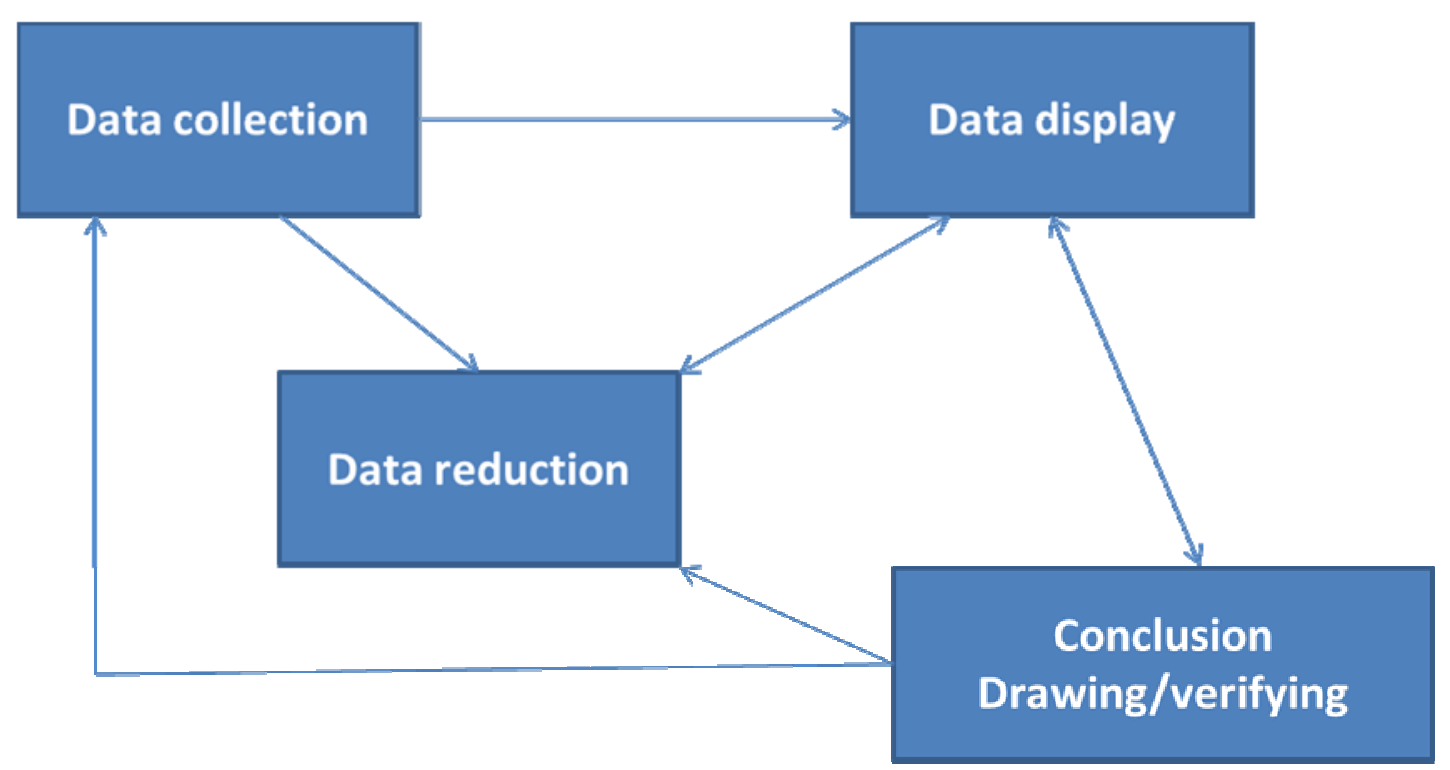

Figure 1. Component of data analysis, interactive model, according to Miles \& Huberman (Miles \& Huberman, 1994, p. 12)

\subsection{Research Method}

As stated above, semi-structured in-depth interviews serve as instrument to collect primary data. The desired information about motivation, practical execution as well as strategic importance of customer segmentation has been gathered by a qualitative research approach.

Top executives such as managing directors or board members of companies are needed to get insights into the main drivers of decisions that drive customer segmentation projects in corporations. Furthermore, only these managers can judge the dimension of such projects as far as planning, timing, execution, cost and mid-term relevance of the results. Convenience sampling as part of the non-probability sampling types has been selected for this research. Executives have been selected according to the ranking of corporations in the sporting goods industry in Europe, based on industry experience and personal contacts of the interviewer. Four top executives agreed to participate in the study, representing four out of the top five companies in the industry.

Due to the strong concentration in the sporting goods industry, the top five companies stand for about $68 \%$ of a global market, whilst the top ten companies own about $84 \%$ of total worldwide sales volume (Handelsblatt, 2013).

The positions of the respondents range from Managing Director and Vice President responsible up to a Chief Executive Officer of multinational corporation level. Therefore representativeness and explanatory power could 
be best provided as these top companies inherit the necessary financial funds as well as human resources to perform long-lasting and strategic projects such as a customer segmentation analysis.

The focus of this research approach lies on the entire dimension of managerial decisions. Access to these decision-makers is granted on personal level to gather direct information in form of an interview. Hence the likelihood that these sources of information respond to a self- completion questionnaire, as often applied in quantitative researches, is very low. Therefore the delicate research topic and the specifics of the respondent group required the selection of a qualitative exploratory research design and the application of personal in-depth interviews to gather reliable primary data. The interviews have been held in person by one of the authors.

\section{Results and Conclusions}

Key statements in the interview sessions have shown that customer segmentation analysis is influencing marketing decisions in sports corporations. A major part of these decisions directly affects the organizational structures, processes and strategies within marketing as well as sales departments. Product innovation and decisions about selective distribution are in direct line with the output of marketing and sales that is influenced by the customer segmentation analysis.

However some results go far beyond the limits of marketing departments and have fundamental consequences within the whole organizational structure of companies, for instance on leadership and change management capabilities.

In summary the key findings of this study within major sporting goods companies comprise five focus areas:

- consumer research and segmentation of distribution channels

- selective distribution

- vertical diversification

- multi-channel marketing

- change requirements

These main findings will be described and elaborated.

\subsection{Consumer Research and Segmentation of Distribution Channels}

The original reason to use customer segmentation as defined by Freter (2008) is the classification of an anonymous, heterogeneous total market into homogeneous groups. The main objective of Freter (2008) is not cost driven but in the increase of sales and margins. This increase is achieved by customization of the range of products offered to end-users within the existing distribution channels.

According to Kerin and Peterson (2007), customer segmentation offers three benefits for companies: Identification of new product opportunities, designing more effective marketing programs and precise allocation of marketing resources.

After evaluation of the collected data, it is conclusive that the practice within the interviewed companies deviates from the generic purpose of the customer segmentation concept. Research results have confirmed that all companies perform market research on a regular basis and therefore the knowledge of consumers demand already exists.

"We need to think more consumer oriented and have to know them much better. What do they like, where are they going to shop sports products? We are in a transition process of thinking more consumer and less distribution channel focussed."

As one result customer segmentation in distribution channels has been conducted in order to understand the different needs and service requirements of sales intermediates.

According to the respondents, it could not be confirmed that there is an ongoing process implemented assuring a linkage of both the consumer research data and customer segmentation analysis. This leads to isolated conclusions on each, the sales and marketing side, which is mainly caused by different responsibilities of each department.

"Sales and Marketing have sometimes isolated thinking and fight more against each other than they cooperate. Both areas need more skills and knowledge from the other side in order to act more consumer and distribution focussed", summarized one respondent the ongoing conflict between sales and marketing.

In practice, sales manager do not have a regularly updated profile of the typical consumer per distribution channel member. Marketing managers know the consumer needs, trends and preferences quite well, but do not 
have knowledge of the characteristics of each distribution channel. Both perspectives are essential input for a strategic marketing and require consolidation on a permanent basis. In particular, consumer needs and purchasing decisions vary much faster in this fashion oriented industry. Today there is not only a summer and winter collection, the trend expands towards intermediate collections for spring and autumn.

In this respect Kotler and Keller (2011) stated that "marketers must segment the market, select the appropriate target and develop the offering's value positioning. The formula segmentation, targeting, positioning (STP) is the essence of strategic marketing" (Kotler \& Keller, 2011, p. 56).

As to STP, Keegan and Green (2010) see segmentation as a first step to the identification and categorization of consumer groups. The second step, which is targeting" (...) reflects the reality that a company should identify those consumers it can reach most effectively, efficiently and profitably" (Keegan \& Green, 2010, p. 237).

Based on the theories of Kotler and Keller as well as Keegan and Green, research was able to provide evidence that the internal communication needs optimization. Relevant consumer research and customer segmentation data have to be merged on a regular basis to raise information quality and improve the input for strategic decisions.

Precise targeting, as well as improved positioning of a sports good company, will lead to a more customized product. Sales and service oriented marketing strategies for each distribution channel are the final and desired output.

Apart from that, the customer segmentation project offers potential to improve efficiency in terms of invested time and marketing resources (Kerin \& Peterson, 2007).

\subsection{Selective Distribution}

The concept of selective distribution allows only a limited number of intermediaries to carry all products of a manufacturer in their product portfolio (Kotler \& Armstrong, 2011). "Selective distribution gives producers good market coverage with more control and less cost than does intensive distribution" (Kotler \& Armstrong, 2011, p. 377).

Sporting goods companies tend to use this distribution policy as they sell increasingly image- and technology driven products. That requires a retail environment which is able to transport the philosophy of branded companies in terms of product presentation, sales capabilities and after sales service.

Distribution channel members have no longer access to the complete range of products of one brand under a selective distribution strategy. Just to those products which can be best presented and sold in that specific type of store are in the offered product portfolio. A football specialist store would not be able to order high end fashion sneakers, as they would not fit the designated product portfolio for that type of shop.

Customer segmentation analysis needs to be filled with consolidated data in order to provide a good basis for accurate marketing decisions. In case this merged data from consumer and distribution factors is not available, there is great potential to improve the distribution correlation at the right point of sale.

"We already practice selective distribution, but many accounts do not accept the impact, if they don't get some hot sellers anymore. That ends very often in reduced orders and in the usual power game", is one CEO describing the possible aftermath of selective distribution. This conflict between retailer and production company shows, that the launch of products at retailers is often coincidence or following the old principle, "the customer gets what he wants".

Even though all interview partners know and apply selective distribution to a certain extent, they do not enforce it to the final extent. Selective distribution should become a leading marketing concept in order to connect targeted consumer groups with customized products through appropriate distribution channels. Precondition for such an approach is a consumer, product and distribution channel matrix, encompassing all strategic business units of a corporation.

\subsection{Vertical Diversification}

E-commerce and internet marketing have a fundamental impact on the structure and design of distribution and marketing channels. The internet has shaken traditional landscapes of intermediaries in many industries to the very foundations. One of these industries is definitely the sporting goods industry.

Traditional small sports retailers have disappeared in frightening pace and large sport department stores or international chains of sports generalist have taken over their market share. However, sports brand manufacturers also operate increasingly as retailers which generated a conflict with their established distribution channels. The 
lack of distribution channels for new- or image driven brand concepts was one reason for a vertical diversification strategy as the interviewees mentioned.

Another reason to get in on the distribution themselves was to escape the pressure of the large international traders with their very profitable trade terms, but very often little interest in adequate brand presentation.

"We have told a big and long-term customer again and again to improve the presentation of our products in their stores. Now we are going to open a 1.000 square meter store next to one of theirs to show them how we understand our brand."

That statement of a Chief executive officer describes a typical situation that major sporting goods manufacturers are often confronted with.

In order to act as a counterbalance, all brand manufacturers interviewed confirmed that they are pushing their vertical distribution plans and opening more retail stores of all kinds, like mono brand driven exclusive flagship-stores, shop-in shop solutions and outlet stores.

Keegan and Green (2010) have added their marketing inspired view to this strategy. "Apple, Levi Strauss, Nike, Sony, well-known fashion design houses and other companies with strong brands sometimes establish flagship retail stores as product showcases or as a means of obtaining marketing intelligence" (Keegan \& Green, 2010, p. 402). Kotler and Armstrong (2011) describe this trend as disintermediation which" (...) occurs when product or service producers cut out intermediaries and go directly to final buyers or when radically new types of channel intermediaries displace traditional ones" (Kotler \& Armstrong, 2011, p. 374).

One executive explained: "We have created a new sub-brand, which we are going to distribute exclusively in our own retail stores. We have done that, because we believe that none of our existing trade partners is in the position to present and sell that product range in an appropriate way. (...) However we still need to learn a lot in the retail business, because our organization is not yet in the position to launch 12 collections per year."

Consequently, all the traditional distribution channels have no access to these new products. This might not only provoke conflicts with the retailers but also with related industries in reducing their market share.

It can further be assumed that the prominent motivation for applying vertical diversification strategies is simply to generate additional sales and a growing margin.

\subsection{Multi-Channel Marketing}

Hybrid-channel or multi-channel marketing is needed when a manufacturer uses more than one distribution channel to reach his target consumer segments. "In multi-channel marketing, each channel targets a different segment of buyers, or different need states for one buyer, and delivers the right products in the right places in the right way at the least cost" (Kotler \& Keller, 2011, p. 439). Kotler and Keller elaborate the objective of a multi-channel strategy, which is fully applicable to the sports industry as well.

Furthermore companies that have to manage multi-channels need to develop individual channel strategies which match the purchasing preferences of each target consumer group. Today's consumers expect integrated channels which allow them to acquire information online and buy offline in another channel. Another demand is to receive discounts for online purchases as customers have the knowledge that online retailers have a reduced cost scenario than shop retailers. Consumer behaviour conditions nowadays a multi-channel strategy which avoids conflicts but allows each channel member a profitable subsistence. In addition to the segmentation of channels, the differentiation of consumer groups shopping in these various channels build the fundament of a strategic marketing mix.

Best (2008) differentiates between seven market segmentation strategies based on the criteria attractiveness, profit potential and available resources. Best's (2008) segment strategies encompass a mass-market strategy, without any different segments, and a sub-segment strategy with a certain number of niche. Sports brands today tend to segment their target consumer base precisely, adding more sub-segments to the already existing 7 to 10 different consumer groups.

Following Best's (2008) segment definition, sports companies need to apply a multi-segment or even a sub-segment strategy for consumer groups and product categories. Taking into account the accelerated globalization of sales and the explosion of direct online sales, international sports corporations are in need of a multi-channel strategy. The executives of sports companies interviewed use between three to five distribution channels namely telesales, wholesale, own retail, global key accounts and e-commerce.

Asked about an "integrated" multi-channel strategy, one manager responded: "We have a so called distribution diamond including six different channels for our wholesale business. We offer for each of them dedicated sales, 
marketing and merchandising teams. Own retail, key accounts and e-commerce have its own distribution policy."

Hence a multi-channel strategy is required, but not existing yet as each channel is managed by a different team. It appears that each channel is handled as an own profit centre.

The interviews revealed ongoing channel conflicts, namely between sports brands, traditional trade and e-traders.

"At the moment many people in the sports market jump on board the internet-train. The reasons are simple: they are making money like hell. We made a big mistake by offering internet dealers the same prices as traditional wholesaler", commented one executive.

Sports companies have not yet dealt with the pricing problem between traditional sports retailers and internet dealers. Taken the different cost situation of these retailer groups in consideration, the traditional sports retail cannot compete with the margin of internet sales in the long run.

The expansion of own retail activities is heating up the pricing discussion once more. Vertical diversification approaches require an even clearer strategic differentiation mainly towards the traditional sports retail channel. A clear strategy on how to target and price the three marketing approaches of own retail, small and independent retail stores and the internet market is urgently required. Otherwise the small retailers will be sacrificed and this leads to even more market power for e-commerce or multinational retail chains. That would bring the producer into a power-game with nebulous outcome.

\subsection{Change-Management}

The interviewees stated that customer segmentation analysis is currently identified as one of the leading projects within their corporations. Two executives even stated that "customer segmentation was becoming company philosophy" and will be developed in the future so that it becomes a permanent and ongoing process. The interviews left no doubt that customer segmentation analysis is of major importance for strategic marketing decisions.

Customer segmentation analysis has also a cultural aspect to the structure of organizations. A change in a company's philosophy has impact on the mindset of its management and employees. In a long term it even influences the corporate culture to a certain extend.

All executives agreed in the statement that changes by customer segmentation projects were of a scale that top management had to lead them. The top management commitment is for such a project of essential impact. The interviews revealed further that on middle and top management level, managers do not have the required skills to assure sustainable success of customer segmentation projects. A need for training could be identified, although the awareness is already existing.

As to change management abilities, one interviewee stated, "during our mid-term planning we found out that we need to improve our change management skills if we want to achieve our ambitious goals. There is silo mentality and adherence to old concepts. Therefore we defined our new way of working and held 120 workshops through all levels of the company, including the board."

Change management and leadership qualification of top executives is of importance for the success. Therefore a training of all levels of a company's structure is necessary to develop the required skills. Goss, Pascale and Athos (1993) emphasised this request by stating that "managers looking for a more fundamental shift in their organizations' capabilities do not need to improve themselves; they need to invent themselves" (p. 83).

All respondents confirmed that a key to success for the implementation of long-lasting change processes is their leadership, in particular by being a positive example.

"Leadership always begins at the top. You are the role model for the rest of the organization", stated one board member in this context.

Duck (1993) described the leading management objective for change processes as “(...) the task (...) to manage the dynamic, not the pieces (...)" and added that, " $(\ldots)$ the goal is to teach thousands of people how to think strategically, recognize patterns, and anticipate problems and opportunities" (p. 2).

Leadership begins at the top. But how are the departments and the employees affected by a change of that scale? The human resources department needs to adapt the new strategy, produce training material and workshops, steers the training demand and reviews the output. Sales and marketing departments are mainly affected by the nature of the project. Strong structural changes and changes in the traditional mindset require flexible and comprehensive employees. Logistics, controlling and IT are in their design as supportive processes also heavily affected by these changes. Vertical distribution and own retail ambitions put an extra pressure on these processes. 
There might well be a high demand for more manpower to handle the new demand to these departments.

In a nutshell the interviewees identified marketing decisions resulting from a customer segmentation analysis mainly in the following areas:

- Re-structuring of the organization and internal interdependencies

These organizational impacts influence mainly the departments marketing, sales, logistics, controlling and IT. Internal and external processes need to be reshaped, the demand for communication increases.

- Changed or new job profiles for the staff

A change of this scope requires differently skilled employees and an adjustment of staff members in various departments. One interviewee expressed his goal: "We need a new qualification for sales and marketing people. They need to have specific strategic skills but understand both, sales and marketing."

- Different product requirements for specific consumer groups

Corporations need to put the mechanisms of selective distribution and vertical diversification operational.

As changes of this extend influence a company's organization and their employees, the design of an internal communication is crucial for the success of this project. Duck (1993) and Martin (1993) recommend that a frequent communication of the project status needs to become a top priority for every manager at all levels of the company. The organization with all their different members needs to be taken into the transition process. No member can be left behind, as this endangers the success of such project by poisoning the mind with old fashioned paradigms. Rethinking the own strategy is a process that needs to be understand from bottom to top. The management commitment gives the top down approach, but even more important is the bottom up channel. The working fundament needs to internalize the new concept and put the new mechanisms operational. A regular communication of success and failure, together with recommended actions has to find its way up to the top. Otherwise will the new management approach with managerial lead only remain a lip service.

\section{Conclusion}

The interviews could identify customer segmentation as an important analytic marketing tool within global sporting goods companies. Customer segmentation analysis delivers a reliable data set for decisions on strategic marketing in distribution channels. It is further an indispensable element for the development of long term strategies. Nevertheless, there is strong uncertainty and lack of orientation within the implementation process in the management.

\section{- The dimensions of the segmentation project are not clearly defined at the beginning.}

Therefore planning of cost and resources and the final results show a wide variation. Strong leadership by a project team is recommended. This team reports directly to the board, provides a project plan at the beginning and monitors all implemented processes continuously. This team should ideally become a permanent institution to adjust the process on regular basis.

- Management commitment, leadership and knowledge of change management skills are key success factors.

These factors are not taken seriously enough by sports companies. The professionalization of customer segmentation needs to be started now, to maximize the results. A halfhearted approach will provoke other market players to replace the sporting goods companies not able to handle the new market requirements.

\section{- A continuous improvement process needs to be implemented.}

The results of customer segmentation analysis need to lead to a consistent adjustment of structures and processes in an organization. Ideally, all stages throughout the whole supply chain of manufacturers are integrated. The correct consolidation of data is an important precondition for delivering valid results out of a customer segmentation analysis.

There is a need for future research to re-design customer segmentation analysis in distribution channels. Terms of definitions, objectives and implementation within commercial practice should be addressed. Influencing factors like increasing globalization efforts, further impact of the internet, accelerated change of consumer habits and the distribution landscape necessitate an adaptation of the segmentation concept. Attention should be paid to quantification of the return on investment. 


\section{References}

Berghoff, H. (2007). Marketing im 20. Jahrhundert. Absatzinstrumente-Managementphilosophie-universelle Sozialtechnik. Marketinggeschichte. Die Genese einer modernen Sozialtechnik (pp. 11-58). Frankfurt A. M.: Campus Verlag.

Best, R. J. (2008). Market-based management. Prentice Hall: Pearson.

Duck, J. D. (1993). Managing Change-The Art of Balancing. (pp. 55-82). Harvard Business Review

Freter, H. (2008). Markt-und Kundensegmentierung (2nd ed.). Stuttgart: Kohlhammer Verlag.

Goss, T., Pascale, R., \& Athos, A. (1993). The Reinvention Roller Coaster: Risking the Present for a Powerful Future. November 1993. Harvard Business Review.

Handelsblatt Online. (2013). Sportartikelhersteller: Nike hängt Adidas ab. Handelsblatt Online.

Keegan, W. J., \& Green, M. (2010). Global Marketing (6th ed.). Prentice Hall: Pearson Education.

Kerin, R. A., \& Peterson, R. A. (2007). Strategic Marketing Problems: Cases and Comments. Prentice Hall: Pearson Education.

Kim, W. C., \& Mauborgne, R. (2005). Blue Ocean Strategy: How to create uncontested market space and make competition irrelevant. Boston, MA: Harvard Business Press.

Kotler, P., \&. Keller K. L. (2011). Marketing Management (14th and global edition). Harlow, England: Pearson Education.

Kotler, P., \& Armstrong, G. (2011). Principles of marketing (14th and global edition). Harlow, England: Pearson Education.

Malhotra, N., \& Dash, S. (2010). Marketing Research An Applied Orientation (6th ed.). India: Pearson Education India.

Martin, R. (1993). Changing the Mind of the Corporation. Harvard Business Review.

Miles, M., \& Huberman, A. (1994). Qualitative data analysis: an expanded sourcebook (2nd ed.). Sage Publications.

Perez, C. (2008). A VISION FOR LATIN AMERICA: A resource-based strategy for technological dynamism and social inclusion (Globelics WP No. WPG0804). UK: Cambridge University.

\section{Copyrights}

Copyright for this article is retained by the authors, with first publication rights granted to the journal.

This is an open-access article distributed under the terms and conditions of the Creative Commons Attribution license (http://creativecommons.org/licenses/by/3.0/). 